\title{
Pilk Tomi kaljutaidele ja petroglüüfide statistikale*
}

Enn Ernits

Võtame ette maakaardi ja reisime mõttes Lääne-Siberi lõunaossa Kemerovo oblastisse. Kuznetski Alatau mäestiku läänenõlvalt saab alguse 840 kilomeetri pikkune maaliline Tom, kõigile teada-tuntud Obi parempoolne lisajõgi. Tomi kaldad koosnevad kõrgetest, järskudest liiva- ja kiltkivikaljudest, millele on hiljem kasvanud seedrid ja männid. Devoniaegne kivim on enamasti värvuselt tumepruun või peaaegu must.

Tomi alamjooksu vertikaalsete kaljude petroglüüfide valmistamise aja kohta käibivad erinevad seisukohad. Tegelikult ongi nad eriaegsed ja võivad pärineda neoliitikumi ja rauaaja vahelisest perioodist (Martõnov \& Lomteva 1994: 18; Okladnikov \& Martõnov 1972: 186, 191).

Tomile iseloomulike põdralaadsete kujutiste neoliitilist algupära (IV-III at eKr) oletas selle piirkonna tunnustatuimaid uurijaid Anatoli Martõnov (Okladnikov \& Martõnov 1972: 183). Teised teadlased on selle aga kahtluse alla seadnud. Peamiselt kõneldakse Tomi petroglüüfide pronksiaegsest päritolust (vt Kovtun 1993: 16 jj).

Kujutiste stiili ja temaatika poolest on Tomi kaljutaie tunduvalt lähemal Ida-Siberi petroglüüfidele kui läänepoolsetele, kuid olulisi erinevusi on isegi Tomi leiuala kujutiste piires (Kovtun 1993: 47). Petroglüüfide lähedusest on leitud paarkümmend arheoloogilist leiukohta (Barinova 1994: 15).

Kaljukujutiste loomisel on kasutatud mitut tehnikat, sageli isegi ühe ja sama petroglüüfi puhul. Seepärast võib Tomi petroglüüfid ehk graveeringud liigitada raiendite, uurendite ja lihvindite hulka. Nende võimalikku usundilist tagapõhja on üksikasjaliselt vaetud A. Okladnikovi ja A. Martõnovi monograafias (1972: 194 jj).

Tomi (Lääne-Siberi) kaljutaide leiuala hõlmab neli üksteisest paljude kilomeetrite kaugusel paiknevat regiooni: 1) Kirjatud kalju,

* Käesolev kirjutis kujutab endast Äänisjärve Luigeneeme leiukoha avastamise 10. aastapäeva minikonverentsil (limnoloogiajaamas Võrtsjärve ääres 14. VII 1996) peetud ettekande olulisel määral täiendatud varianti. 


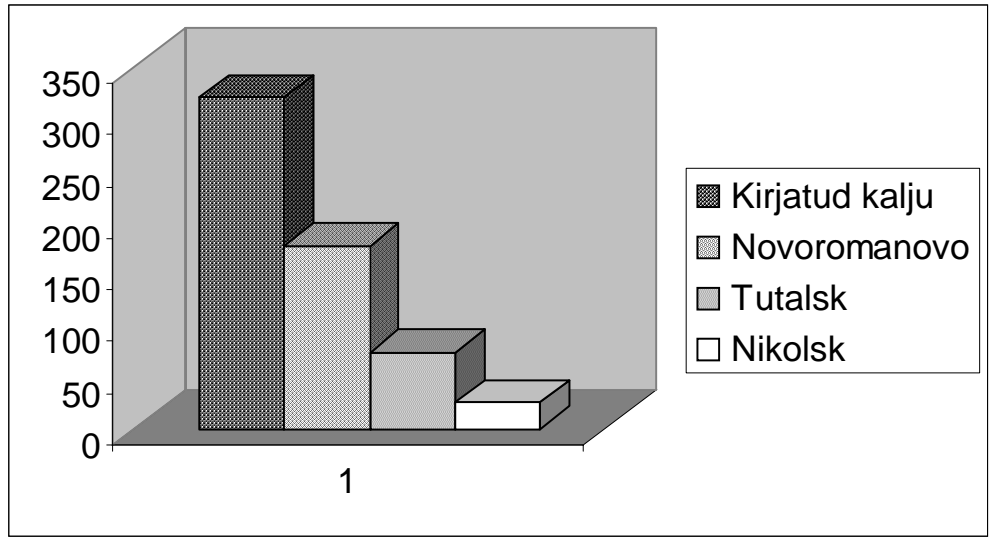

Joonis 1. Tomi petroglü̈̈fide arv regiooniti.

2) Novoromanovo (Novoromanovo I ja II ning Rippuva kalju leidkonnaga), 3) Nikolsk ja 4) Tutalsk. Väiksemate jaotuste kohta on uurijad kirjasõnas kasutanud erinevaid mõisteid, mille ühtlustamine pole käesoleva töö ülesandeks.

Tomi jõe kaljuseintelt saab kirjanduse andmeil loendada 596 muistset graveeringut. Arvestamata on jäetud muinasajast hilisemad ruunikirjamärgid. Kujutiste tegelik arv on suurem, sest pole teada 1995. aastal Tutalski viielt paneelilt avastatud petroglüüfide arvu ja osa andmeid on umbkaudsed, sest seni ilmunud kirjanduses peetakse kompositsioone sageli üheks petroglüüfiks, kuid ilma kohapealsete uuringuteta ei saa nende arvu täpsustada. Seega võiks Lääne-Siberis arvestada vähemalt 650 säilinud kujutisega, aga võib-olla isegi rohkemaga. Petroglüüfide säilimise aste on erinev. Aja jooksul on graveeringuid tohutul hulgal hävinud.

Kõige suurem leiuala on Kirjatud kalju 320 säilinud petroglüüfiga, mis moodustab 53,6\% nende koguarvust Tomi kallastel (joonis 1). Suuruse poolest teisele kohale jääb Novoromanovo regioon, kus on leitud vähemalt 177 kujutist (29,7\%). Sellest mitu korda pisemad on Tutalski ( 74 graveeringut ehk 12,4\%) ja eriti Nikolski (25 ehk 4,2\%) kaljutaideregioon.

Teadaolevalt pole Tomi petroglüüfide liigilist koosseisu ja osatähtsust seni statistiliselt käsitletud. Paraku saab käesolevaski opereerida vaid arvuga 517 (s.t 596-29-25-25), sest siinkirjutajale pole teada ei 1991. aastal avastatud Novoromanovo I petroglüüfide (29) 
ega Novoromanovo II ja Nikolsk leidkonna liigiline koosseis (kummaski umbes 25 kujutist).

Esmakordselt on Tomi kaljutaide käsitlemisel kasutatud uut terminoloogiat. Petroglüüfide nimetused lähtuvad nende prototüübi kreekakeelsest nimetusest, millele on lisatud võõrosis -morf (vt Poikalainen \& Ernits 1998: 49) või eestipärane -laadne (petroglüüf), sest pole näiteks teada, kas karulaadne kujutis esindab looduslikku karu või karusarnast jumalust.

Kui kujutistel ei saa määrata prototüüpi, on ta liigitatud määramatute rühma. Määratud ehk identifitseeritud petroglüüfid kujutavad kas elusolendeid (biomorfid) või eluta olendeid (abiomorfid). Biomorfid võivad esindada kas inimesi (antropomorfid), loomi (zoomorfid) või taimi. Etteruttavalt võib öelda, et Tomil taimelaadsed kujutised puuduvad.

Zoomorfsed petroglüüfid võivad kajastada inimese- või loomalaadseid olendeid ka osaliselt. Näiteks leiduvad Tomil inimnäolaadsed (tõenäoliselt maskidena) ja loomapealaadsed kujutised (sageli kaeltega). Neid on käesolevas töös nimetatud tsefalomorfideks.

Tabelites ja diagrammides kajastuvad vaid viis sagedasimat petroglüüfiliiki. Muulaadsete rühma on paigutatud suhteliselt harva esinevad, kuid seetõttu eriti väärtuslikud petroglüüfid. Asjaomases rühmas leiduvad ka vähesed täpsemini diferentseerimatud imetajalaadsed kujutised (teriomorfid).

\section{Kirjatud Kalju}

Piki Tomi jõge allavoolu sõites jõuame Kemerovost 60 kilomeetri kaugusel paremal kaldal lisajõe Pissanaja suudmealal esimese kaljutaide regioonini, mida kutsutakse Kirjatud kaljuks (vene keeles Pissannõi Kamen, samuti ka Tomskaja Pissanitsa).

A. Okladnikovi ja A. Martõnovi andmeil (1972) olevat Tomi Kirjatud kaljut esimesena kirjeldanud keegi vene rändur XVII sajandil. Raamatus on seda leiukohta käsitlenud Põhjasõja ajal Poltava lahingus venelaste kätte vangi langenud Filipp Johann Tabbert, hilisema nimega Strahlenberg, kes osales aastail 1721-1722 doktor D. Messerschmidti ekspeditsioonil. Oma reisikirjelduse avaldas ta Stockholmis 1730. aastal.

Kirjatud kalju hõlmab 10 leiukohta (I-VII on kaljuosad ehk paneelid või pannood, VIII-X aga kaljupangad) (joonis 2). Rohkesti petroglüüfe on hävinud. 


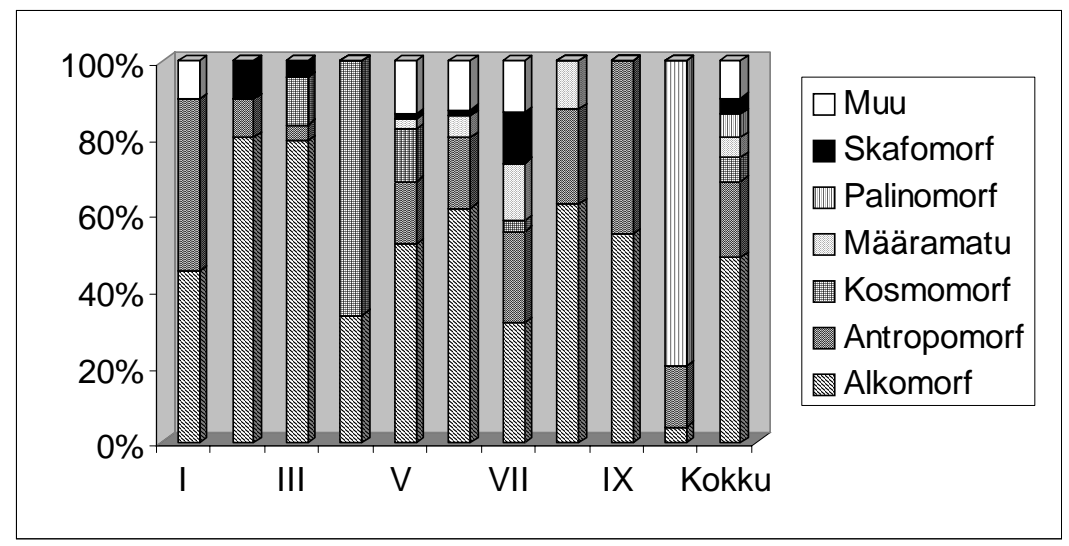

Joonis 2. Kirjatud kalju petroglü̈̈id.

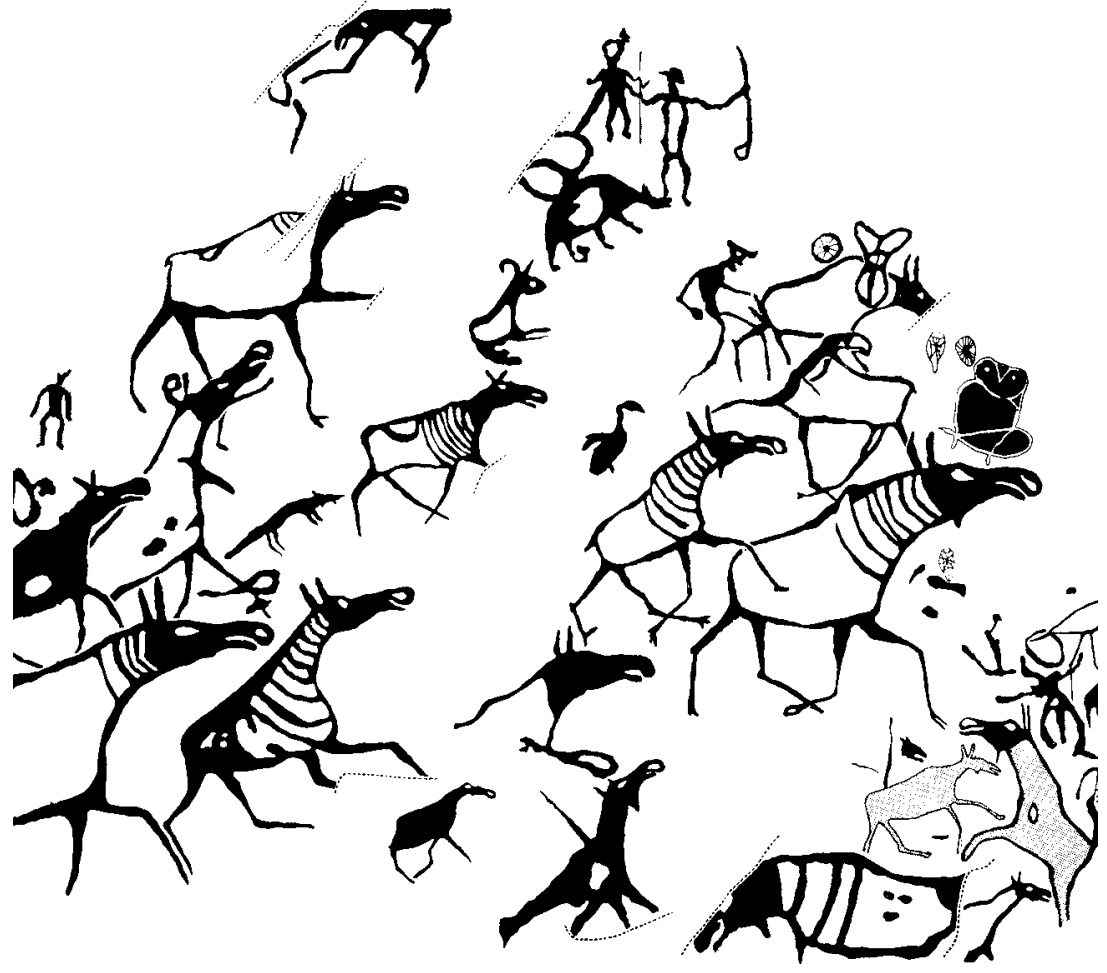

Joonis 3. Kirjatud kalju III paneel (Okladnikov \& Martõnov 1972: 70 ja 71 vahel). 
Esimese leiukoha (kaljuosa) 20 petroglüüfist on 9 põdralaadset kujutist ehk alkomorfi (45\% leiukoha graveeringute arvust). Neist $66,7 \%$ moodustavad põdrapeakujutised ehk alkotsefalomorfid. 9 kujutist on inimlaadsed ehk antropomorfid (45\%). Veel on kirjeldatud üks linnulaadne ehk ornitomorf, üks koerakujutis ehk künomorf ja üks linnu- või inimesekujutis, mis käesolevas tabelis on ta paigutatud viimaste hulka.

Teises leiukohas on avastatud vaid 10 kujutist, millest enamiku moodustavad alkomorfid (80\%). Sealt on leitud ka üks antropomorf ja üks paadikujutis ehk skafomorf.

Kolmandas leiukohas (24 petroglüüfi) on ülekaalus alkomorfid (19 ehk 79\%), neist 7 ehk 37\% kujutavad endast tsefalomorfe (joonis 1). Seal on kirjeldatud ka 3 ringilaadset kujutist (12,5\%). Nii ringi- kui ka ovaalilaadsed figuurid on käesolevas töös oletamisi liigitatud kosmomorfide kilda. Peale selle näeme nimetatud leiukohas veel üht antropo- ja üht skafomorfi.

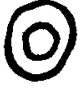

Neljas leiukoht 6 petroglüüfiga on väikseim. Seal on registreeritud vaid kaks alkomorfi ja 4 ringilaadset kujutist (kosmomorfid) (joonis 4).

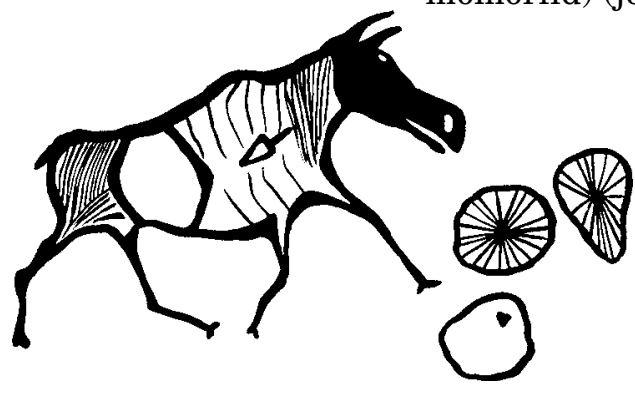

Joonis 4. Põdralaadne kujutis ja kosmomorfid Kirjatud kalju IV leiukohast (Okladnikov \& Martõnov 1972: 48).

Joonis 5. Antropomorf, alkomorfja skafomorf Kirjatud kalju V paneelilt (Okladnikov \& Martõnov 1972: 73).

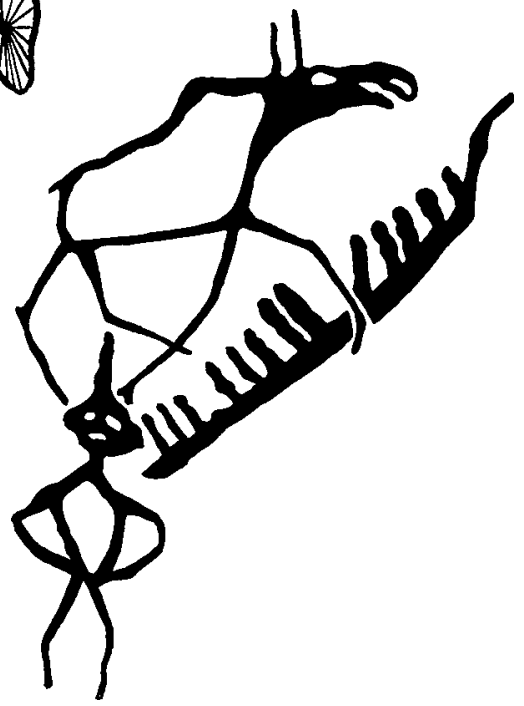


Viies leiukoht (joonis 5) on Kirjatud kalju regioonis suurim (79 petroglüüfi ehk $24,7 \%$ regiooni kujutistest). Seal leidub kõige rohkem alkomorfe (41 ehk ligemale 52\% leiukoha petroglüüfidest), millest peakujutisi on kõigest kolm. Sageduselt teisel kohal on inimlaadsed kujutised $(16,4 \%)$, sh leidub üks antropotsefalomorf, veidi vähem on ringi- ja ovaalikujutisi $(13,9 \%)$.

Samapalju on viiendas rühmas muulaadsete rühma paigutatud petroglüüfe. Nende hulgas pakuvad huvi neli linnulaadset kujutist (5,3\% leiukoha petroglüüfidest), sh üks öökullilaadne, kolm karulaadset ehk arktomorfi (3,8\%), koera- või jäneselaadne, mingi imetajalaadne ning abiomorfidest sirklitaoline ja võrkjas moodustis. Leiukoht on seega rikas haruldaste kujutiste poolest. Tavalistest petroglüüfidest väärib tähelepanu veel üks venelaadne.

Kuues leiukoht on suuruselt teisel kohal. Sealgi on kõige enam alkomorfe, mis moodustavad 69 kujutisest 43 ehk 62,3\%. Viimaste hulgas leidub haruldaselt palju alkotsefalomorfe (21 ehk 48,9\%). Antropomorfe on 10 (14,5\%), kuid tsefalomorfe on nende hulgas vaid kolm. Mainimata ei saa jätta üht skafomorfi. Seal leidub haruldaste biomorfidena veise-, jänese- ja karulaadne petroglüüf ning ilmselt abiomorfidena neli arusaamatu sisuga tähni (5\%).

Seitsmenda leiukoha petroglüüfid on üheks Kirjatud kalju kolmest suuremast rühmast. 67 petroglüüfi seas domineerivad alkomorfid (21 ehk 31,3\%, sh 8 tsefalomorfi), antropomorfid (16 ehk ligemale $24 \%$, sh 4 tsefalomorfi) ja määramatud kujutised (10 ehk 14,9\%). Üheski teises Tomi leiukohas ei esine niipalju venekujutisi (9 ehk 13,4\%).

Seitsmendas leiukohas on täheldatud kaks kosmomorfi. Haruldasemate petroglüüfide hulka kuuluvad nimetatud leiukohas üks oina- või soku-, hirve-, jänese-, koeralaadne, mingi teriomorf, kaks arktomorfi ja kaks tähni. XVIII sajandil olevat siin märgatud isegi kalakujutist (Okladnikov \& Martõnov 1972: 96).

Kaheksandas leiukoha petroglüüfidest on enamik ajapikku hävinud, registreeriti vaid 5 põdrakujutist (61\%), 2 antropomorfi (33\%) ja üks määramatu kujutis.

Üheksanda, suhteliselt väikese, 11 petroglüüfist koosneva leiukoha moodustavad 6 alko- ja 5 antropomorfi.

Kümnenda leiukoha 25 petroglüüfi kajastavad põdrajahti. Nende hulgas on esikohal ajujahiga seonduva aediku vaiu meenutavad kujutised (14 ehk 58,7\%). Samas leiukohas on täheldatud 5 figuuri, mis võivad kujutada loendusel kasutatavaid pulki (20\%). Viimati mainitud figuuride kuulumine muinasaega pole kindel. Seega moo- 
dustavad asjaomase kaljupanga palinomorfid (kepilaadsed figuurid) $78,7 \%$. Peale ühe alkomorfi näeme kaljul kaht kindlat antropomorfi vibulaadse moodustisega ja kaht üpris kaheldavat inimlaadset figuuri (või loenduspulka?).

Kokku on Kirjatud kaljul 320 petroglüüfi, millest ligemale poole (155 ehk 48,6\%) moodustavad alkomorfid. Teisel kohal on inimlaadsed kujutised (64 ehk 20,1\%), mida on siiski üle kahe korra vähem kui põdralaadseid figuure. Mõlemad protsendid vastavad Tomi leiuala keskmisele. Eks määra ju Kirjatud kalju kõige suurema leiukohana olulisel määral keskmist protsenti.

Ringikujulisi ja ovaalseid kujutisi ehk kosmomorfe (kokku 20 ehk 6,25\%), palinomorfe (20 ehk 6,25\%), määramatuid kujutisi (17 ehk 5,3\%) ja skafomorfe (13 ehk 4,1\%) täheldatakse (v.a skafomorfid) Kirjatud kaljul enamvähem võrdselt (5-6\% piires). Taralatte meenutavaid kujutisi esineb peale selle veel Tutalski leiukohas, ent loenduspulgalaadseid petroglüüfe on leitud üksnes Kirjatud Kaljult.

Ülejäänud petroglüüfid (31) moodustavad Kirjatud kalju petroglüüfidest kokku vaid 9,7\%. Seal on seni registreeritud 6 (1,9\%) arktomorfi, 6 linnukujutist, sh $4 \mathrm{~V}$ leiukohas. Nii ornitomorf kui ka arktomorf esinevad peale Kirjatud kalju veel Novoromanovo II leidkonnas ja Tutalskis; üks ornitomorf ka Novoromanovo I leidkonnas.

Väga haruldased on koera või jänest, veist ja väikemäletsejat kujutavad graveeringud. Koeralaadseid figuure on vaid kaks, lisaks veel üks kas koera või jänest kujutav petroglüüf. Ka jäneselaadseid on Kirjatud kaljul ainult kaks ja Tomi kaljutaides neid mujal ei esinegi. Lammast või kitse meenutav petroglüüf on teada ka Novoromanovo I leidkonnas. Üks kujutis on identifitseeritud hirveks, teine veiseks (pulliks). Needki on unikaalsed.

Abiomorfidest on talletatud vähesel määral arusaamatu sisuga tähne (6), kaks sirkeljat moodustist (võib-olla saab neid paigutada kosmomorfide alla; kaks kujutist ka Novoromanovo I) ning täiesti ainulaadset võrkjat struktuuri.

\section{Novoromanovo regioon}

See kaljutaideregioon hõlmab siinkirjutaja hinnangul kolme suhteliselt lähestikku paiknevat leidkonda: Novoromanovo I ja II ning Rippuv kalju. 


\section{Novoromanovo I}

Novoromanovo I leidkond (vene Novoromanovskaja Pissanitsa) paikneb Kirjatud kaljust 26 km kaugusel Tomi paremal kaldal Dolgaja jõe suudmealal ja sai teadusele tuntuks 1967. aastal A. Martõnovi juhitud ekspeditsiooni käigus. Petroglüüfid asuvad 100 meetri pikkusel alal. Monograafias on kirjeldatud 54 graveeringut, ent nende hulgas on mitu palimpsesti või kompositsiooni, mille osad on üksteisega kokkupuutes. Näiteks teises leiukohas on kirjeldatud 10 petroglüüfi, kuid tegelikult ulatub nende arv 20ni (vrd Okladnikov \& Martõnov 1972: 129-131). Seepärast saime 1967. aastal avastatud petroglüüfide koguarvuks 86. Leiukohad (paneelid) paiknevad üksteisest 3-4 meetri kaugusel.

1991. aasta suvel inspekteeriti Novoromanovskaja Pissanitsat teist korda. Avastati uusi kujutisi ja täpsustati varasemate leidude kontuure. Pärast seda on juttu tehtud nelja rühma jaotuvast 72 petroglüüfist 15 paneelil (Martõnov \& Lomteva 1994: 18). Paraku pole esitatud nende rühmasisest statistikat. Seepärast saab käesolevas ülevaates lähtuda vaid eespool mainitud koguarvust 86 (joonis 6).

Esimeses leiukohas, mis on teadaolevalt Novoromanovo pisim, on loetletud üksnes 7 kujutist, millest neli on alkomorfid (57\%) ja üks liigiliselt eristamatu teriomorf. Peale selle on nimetatud leiukohas kirjeldatud veel kaht skafomorfi.

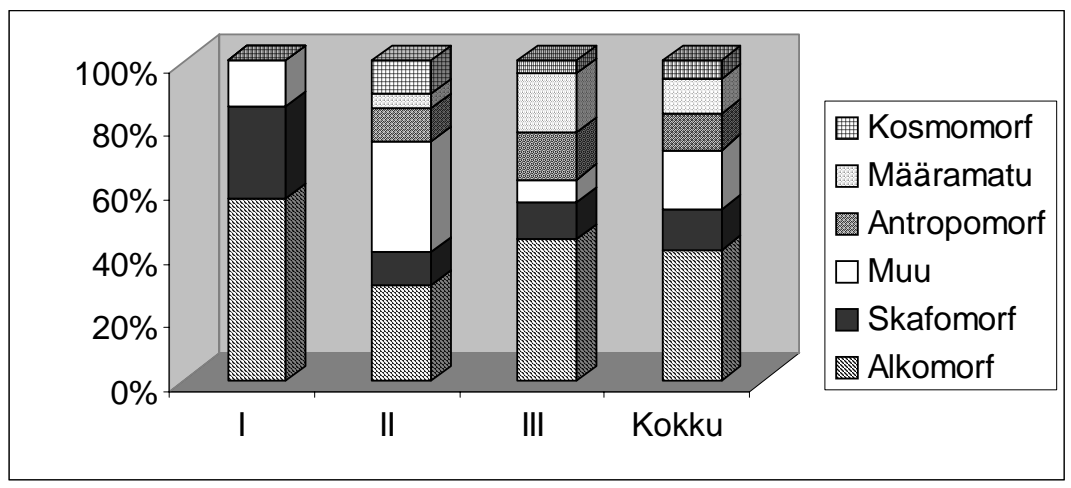

Joonis 6. Novoromanovo I petroglü̈̈fid. 


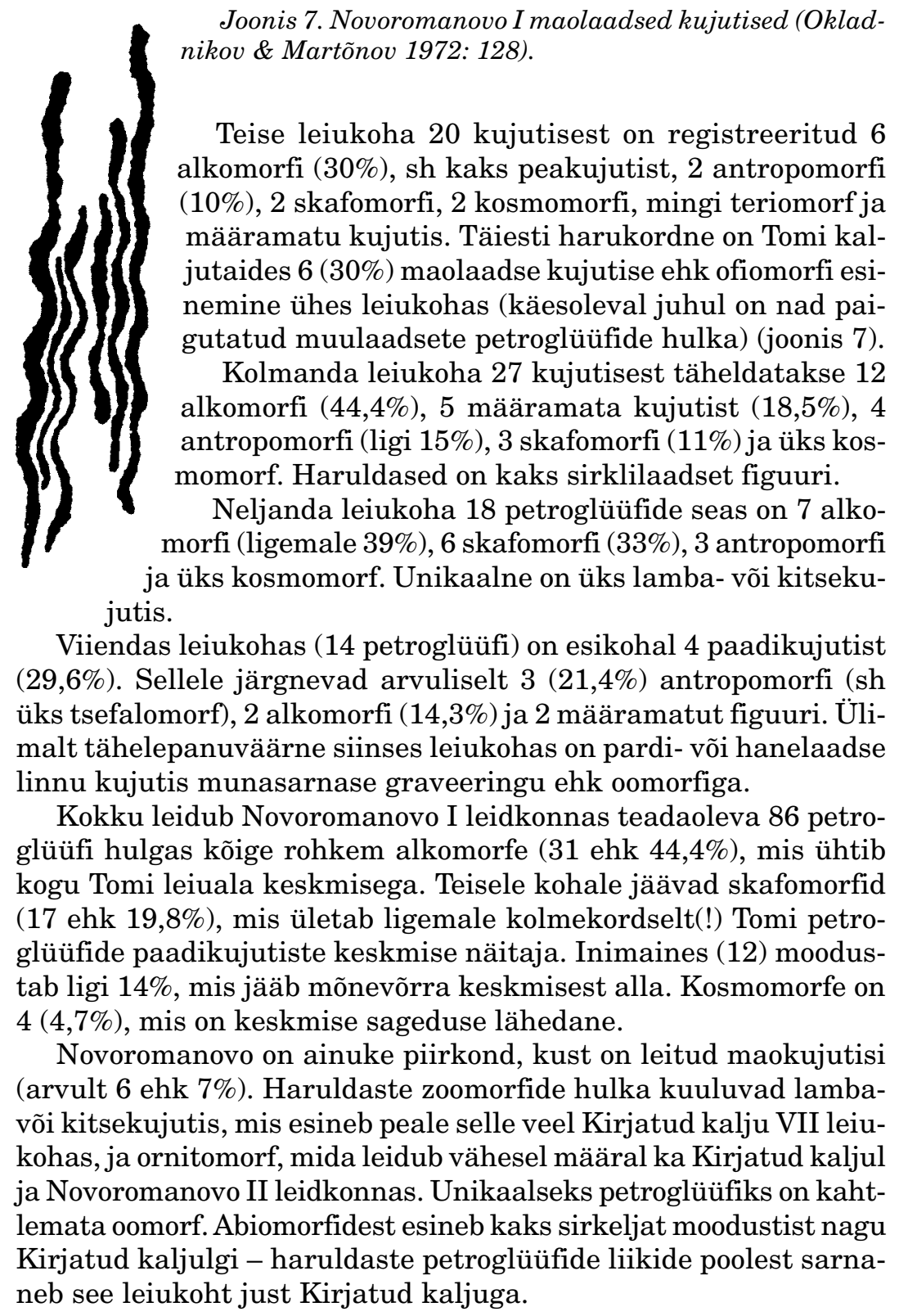

nikov \& Martõnov 1972: 128).
Teise leiukoha 20 kujutisest on registreeritud 6
alkomorfi $(30 \%)$, kh kaks peakujutist, 2 antropomorfi (10\%), 2 skafomorfi, 2 kosmomorfi, mingi teriomorf ja määramatu kujutis. Täiesti harukordne on Tomi kaljutaides 6 (30\%) maolaadse kujutise ehk ofiomorfi esinemine ühes leiukohas (käesoleval juhul on nad paigutatud muulaadsete petroglüüfide hulka) (joonis 7).

Kolmanda leiukoha 27 kujutisest täheldatakse 12 alkomorfi $(44,4 \%), 5$ määramata kujutist $(18,5 \%), 4$ antropomorfi (ligi 15\%), 3 skafomorfi (11\%) ja üks kosmomorf. Haruldased on kaks sirklilaadset figuuri.

Neljanda leiukoha 18 petroglüüfide seas on 7 alkomorfi (ligemale 39\%), 6 skafomorfi (33\%), 3 antropomorfi ja üks kosmomorf. Unikaalne on üks lamba- või kitsekujutis.

Viiendas leiukohas (14 petroglüüfi) on esikohal 4 paadikujutist $(29,6 \%)$. Sellele järgnevad arvuliselt $3(21,4 \%)$ antropomorfi (sh üks tsefalomorf), 2 alkomorfi (14,3\%) ja 2 määramatut figuuri. Ülimalt tähelepanuväärne siinses leiukohas on pardi- või hanelaadse linnu kujutis munasarnase graveeringu ehk oomorfiga.

Kokku leidub Novoromanovo I leidkonnas teadaoleva 86 petroglüüfi hulgas kõige rohkem alkomorfe (31 ehk 44,4\%), mis ühtib kogu Tomi leiuala keskmisega. Teisele kohale jäävad skafomorfid (17 ehk 19,8\%), mis ületab ligemale kolmekordselt(!) Tomi petroglüüfide paadikujutiste keskmise näitaja. Inimaines (12) moodustab ligi $14 \%$, mis jääb mõnevõrra keskmisest alla. Kosmomorfe on $4(4,7 \%)$, mis on keskmise sageduse lähedane.

Novoromanovo on ainuke piirkond, kust on leitud maokujutisi (arvult 6 ehk 7\%). Haruldaste zoomorfide hulka kuuluvad lambavõi kitsekujutis, mis esineb peale selle veel Kirjatud kalju VII leiukohas, ja ornitomorf, mida leidub vähesel määral ka Kirjatud kaljul ja Novoromanovo II leidkonnas. Unikaalseks petroglüüfiks on kahtlemata oomorf. Abiomorfidest esineb kaks sirkeljat moodustist nagu Kirjatud kaljulgi - haruldaste petroglüüfide liikide poolest sarnaneb see leiukoht just Kirjatud kaljuga. 


\section{Novoromanovo II}

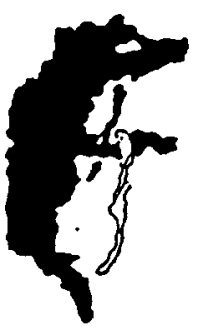

Novoromanovo II asetseb eelmisest leidkonnast ligikaudu ühe kilomeetri kaugusel. See avastati kaitsealamuuseumi Tomi Kaljukujutised ekspeditsiooni käigus 1993. aasta suvel (Barinova \& Rusakova 1995). Seal on kirjeldatud 8 paneelil 25 petroglüüfi. Leidkonna alko- ja skafomorfid sarnanevad Kirjatud kalju omadega. On avastatud ka antropo- ja kosmomorfe.

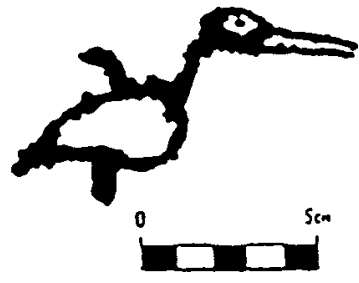

Haruldaseks graveeringuks osutus üks arkto- ja üks ornitomorf (joonis 8). Unikaalseks peetakse üht tõrrelaadset kujutist. Lähedusest leitud savipottide motiivide põhjal oletatakse, et Novoromanovo II petroglüüfid on loodud pronksiaja alguses (Barinova \& Rusakova 1995: 19).

Joonis 8. Karu-ja linnukujutis Novoromanovo II leidkonnast (Barinova \& Rusakova 1995: 18).

\section{Rippuv kalju}

Rippuv kalju (vene keeles Visjaštši Kamen) avastati 1991. aasta augustis kaitsealamuuseumi Tomi Kaljukujutised ekspeditsioonil I. Kovtuni juhtimisel (Kovtun 1993). See paikneb Novoromanovo regioonist 1,5 (teistel andmetel kolme) kilomeetri kaugusel Tomi pidi allavoolu sõites parempoolsel kaljumassiivil Novoromanovo asula vastas üle jõe. Petroglüüfid, mis jäävad suviti 1,5-4 meetri kõrgusele veepinnast, on loodud uurijate arvates alates hilisneoliitikumist hilispronksiajastuni, s.t III aastatuhande lõpust esimese aastatuhande alguseni eKr (Barinova 1994: 18).

Regiooni neli leiukohta paiknevad üksteisest 25-120 meetri kaugusel (90-300 m, Barinova 1994: 15 järgi). Petroglüüfe on registreeritud poole kilomeetri pikkuselt alalt, kuid enamik neist paikneb 80-90 meetri pikkusel kaljupinnal (Kovtun 1993: 4; joonis 9). Peale selle leidub nimetatud regioonis arvukalt petroglüüfikatkeid, mida uurijad pole vähese informatiivsuse tõttu kirjasõnas avaldanud (Kovtun 1993: 8). 


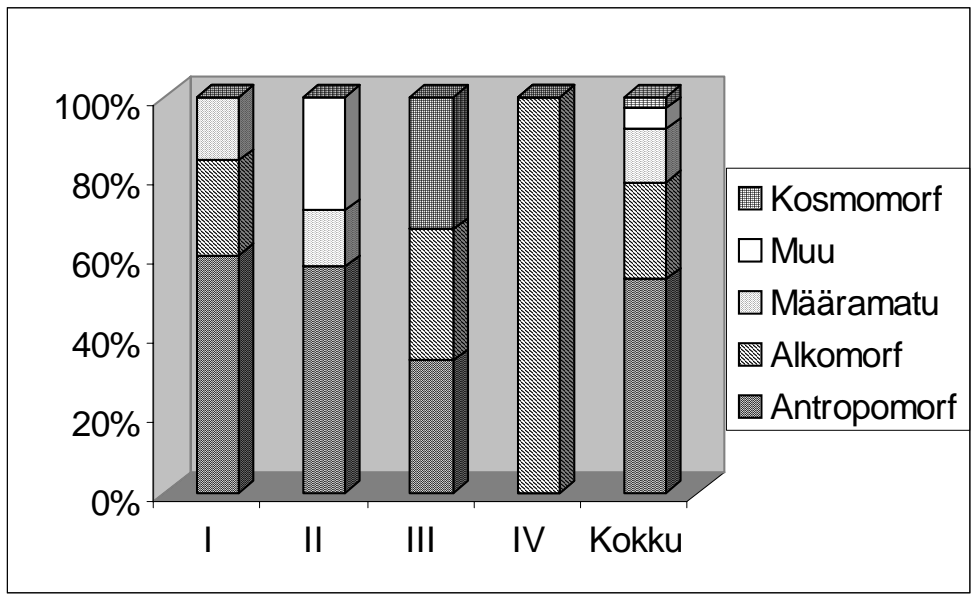

Joonis 9. Rippuva kalju petroglü̈̈fid.

Esimese leiukoha moodustavad 7-8 paneeli. 25 petroglüüfi hulgas on esikohal antropomorfid (15 ehk 60\%). Nende seas leidub rekordiline arv, nimelt 12 maskilaadset petroglüüfi, mis moodustab $80 \%$ antropomorfsetest kujutistest. Alkomorfe on kõigest $6(24 \%)$. Siinses rühmas leidub ka 4 identifitseerimata kujutist (16\%).

Teises leiukohas, mis asetseb eelmisest 50-55 m kaugusel Tomist ülesvoolu, on paaril paneelil registreeritud ühtekokku 7 kujutist, millest neli on antropomorfid $(57,1 \%)$, kaks mingisugust teriomorfi ja üks osalise säilimise tõttu identifitseerimatu kujutis.

Kolmandas leiukohas, mis paikneb eelmisest 25-30 m ülesvoolu, moodustavad enamiku ajaloolisest ajast pärinevad ruunimärgid (81\%), mis jäetakse käesolevast statistilisest analüüsist välja. Muinasaega kuuluvad vaid üks antropo-, alko- ja kosmomorf.

Neljanda leiukoha (eelmisest leiukohast $300 \mathrm{~m}$ ülesvoolu) moodustavad vaid kaks alkomorfi.

Kokku on Rippuval kaljul säilinud 37 muinasaja petroglüüfi. Kõige sagedasem on inimaines

Joonis 10. Antropotsefalomorf Rippuvalt kaljult (Barinova 1994: 16).

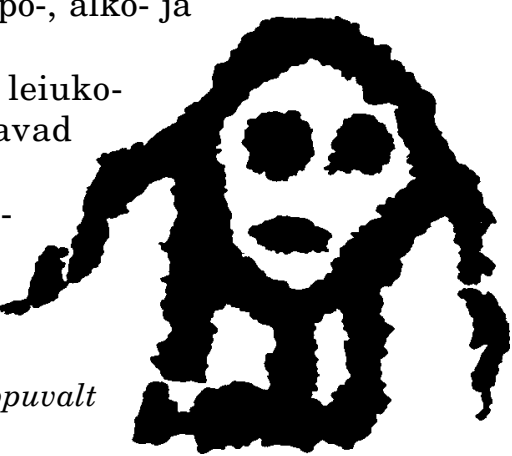


(20 graveeringut ehk 54\%), eriti maskilaadsed antropotsefalomorfid, mis ületab Tomi kaljutaideala asjaomase keskmise näitaja ligemale kolmekordselt (joonis 10). Maskoidid jagunevad ümmargusteks ja südamekujulisteks (Kovtun 1993: 13).

Teisele kohale jäävad alkomorfid, mida on eelmistest üle kahe korra vähem (9 ehk 24,3\%). Neid on Tomi keskmisest peaaegu kaks korda vähem. Kosmomorfe on leitud vaid üksainus. Rippuva kalju üheks omapäraks on ka muulaadsete kujutiste (skafomorfid jt) puudumine.

\section{Nikolski regioon}

Tomi lisajõge Nikolskajat pidi ülesvoolu sõites leiame Nikolski regiooni, mis paikneb Novoromanovo II leidkonnast 15 kilomeetrit allavoolu. Selle avastas I. Kovtun 1991. aastal või kaitsealamuuseumi Tomi Kaljukujutised ekspeditsioon 1993. aasta suvel (Kovtun 1993: 15; Barinova \& Rusakova 1995). Viielt paneelilt leiti ühtekokku 25 petroglüüfi. Nende hulgas tuntakse alkomorfe ja seni esmakordselt avastatud skemaatilisi teriomorfe (sõralised?), samuti skafomorfe. Harukordseteks peetakse vibumehe kujutist. Petroglüüfid näivad pärinevat kahest perioodist. Kujutiste arvuline koosseis on siinkirjutajale teadmata.

\section{Tutalski regioon}

Tutalski regioon (samanimelise sanatooriumi järgi) paikneb Novoromanovost $26 \mathrm{~km}$ kaugusel Tomi paremal kaldal pisikese Rudniki küla lähedal, üle jõe paistva Jurga linna vastas (Okladnikov \& Martõnov 1972: 143 jj). Tom teeb seal kandis järsu käänu põhja poole ja voolab edaspidi madalate kallaste vahel. Tutalski regioonist on teada kuus leiukohta (joonis 11).

Esimese leiukoha avastasid A. Okladnikov ja A. Martõnov 1967. aasta sügisel. Seal on 28 kujutist, nende hulgas kolm (10,71\%) halvasti säilinud ookrimaalingut (alkomorf, oletatav hipomorf ehk hobuselaadne kujutis ja mingi teriomorf). Maalinguid pidas A. Okladnikov vanemal kiviajal tehtuteks. Sellele oletusele on aga tõsiselt vastu vaieldud (Kovtun 1993: 23). Kujutistest esikohal on 25 alkomorfi $(89,29 \%)$, mille seas leidub 5 peakujutist (alkomorfidest $20 \%$ ). Peale selle on seal kirjeldatud antropomorfi ja mingit teriomorfi. 


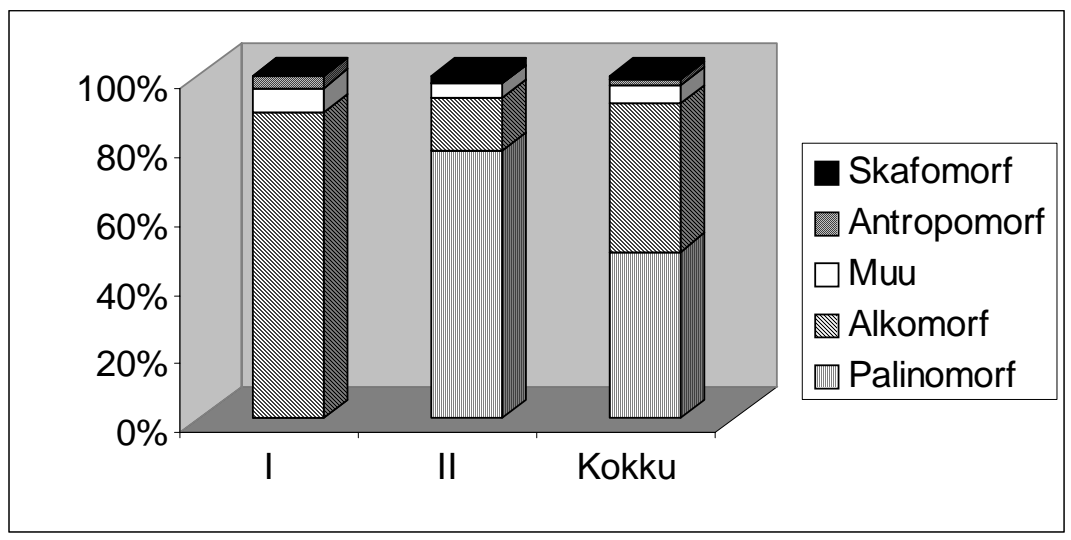

Joonis 11. Tutalski petroglüüfid.

Teise leiukoha avastas N. Ovtšinnikov 1906. aastal. Seal on muinasaja arvukatest petroglüüfidest säilinud vaid 46; neistki moodustavad enamiku (36 ehk 78,7\%) taralatilaadsed kujutised, mida on peale selle veel teada Kirjatud kalju regioonist. Kui need välja arvata, siis on teises leiukohas tegu põhiliselt alkomorfidega (7 graveeringut 10st). Leidub veel skafomorf ja karukujutis; viimast on leitud vähesel määral Kirjatud kalju V-VII leiukohas, Novoromanovo II ja Nikolski leidkonnas.

Kokku on Tutalski regioonis statistiliselt arvestatavad 74 petroglüüfi, enim on taralatilaadseid kujutisi (36 ehk 48,7\%) ja teisel kohal on ootuspäraselt alkomorfid (32 ehk 43\%), mille hulgas osakujutised (alkotsefalomorfid) moodustavad ligikaudu veerandi. Põdralaadsete kujutiste protsent on lähedane Tomi leiuala keskmisele. Tutalski esimeses leiukohas on üle kolme korra rohkem alkomorfe kui teises leiukohas.

Antropomorfe (1) on selles regioonis Tomi keskmisest näitajast 10 korda vähem. Latilaadseid graveeringuid on leitud Kirjatud kalju ühes leiukohas. Haruldane on arktomorf, mida esineb veel ainult Kirjatud kaljul.

Neli leiukohta või paneeli avastas kaitsealamuuseumi Tomi Kaljukujutised ekspeditsioon 1993. aasta suvel (Barinova \& Rusakova 1995: 19). Kahjuks pole siinkirjutajale teada nende liigiline koostis. Kolmel paneelil on kujutatud põtru nagu Tomi teistes leiupaikades, neljandal paneelil aga mingeid teriomorfe (sõralisi?) nagu Nikolski regiooni kaljul. 


\section{Kogu leiuala}

Lääne-Siberis Tomi jõe ääres on rohkesti petroglüüfe aja jooksul hävinud ning osa kohta pole siinkirjutajal vajalikke andmeid. Loodetavasti ei muuda see aga oluliselt kogu leiukoha kujutiste statistikat.

Käesolevas ülevaates olid statistiliselt kasutatavad vaid 517 petroglüüfi, millest ligi poole moodustavad alkomorfid (227 ehk $43,9 \%$; neist peakujutised ligemale $22 \%$; joonis 12 ). Kokku leidub Tomil zoomorfseid kujutisi veidi üle poole $(51,5 \%)$ petroglüüfide koguarvust.

Sageduselt teisele kohale jäävad inimlaadsed kujutised (97 ehk 18,8\%), millest maskilaadsed moodustavad ligi kolmandiku. Loomakujutistest suhteliselt haruldased on arktomorfid ja ornitomorfid (kumbagi 7 ehk 1,35\%, lisaks ka Novoromanovo II; kokku kahes regiooni neljas leiukohast) ning ofiomorfid ( 6 ehk 1,16\%; ühes leiukohas). Väga haruldaste hulka kuulub koera-, jänese-, lamba- või kitse- ja hirvelaadsete olendite kujutamine. Zoo- ja antropomorfide summeerimisel saame biomorfide arvuks 363 ehk $70,2 \%$.

Tomi petroglüüfide seas leidub teadaolevalt 124 (23,9\%) abiomorfi. Suhteliselt palju on põdrapüügiga seonduvaid taralatikujutisi, samuti loenduspulkade omi (kokku 56 ehk 10,8\%), skafomorfe (31 ehk 6\%) ja oletatavaid kosmomorfe (kokku 26 ehk 5\%). Ülejää-

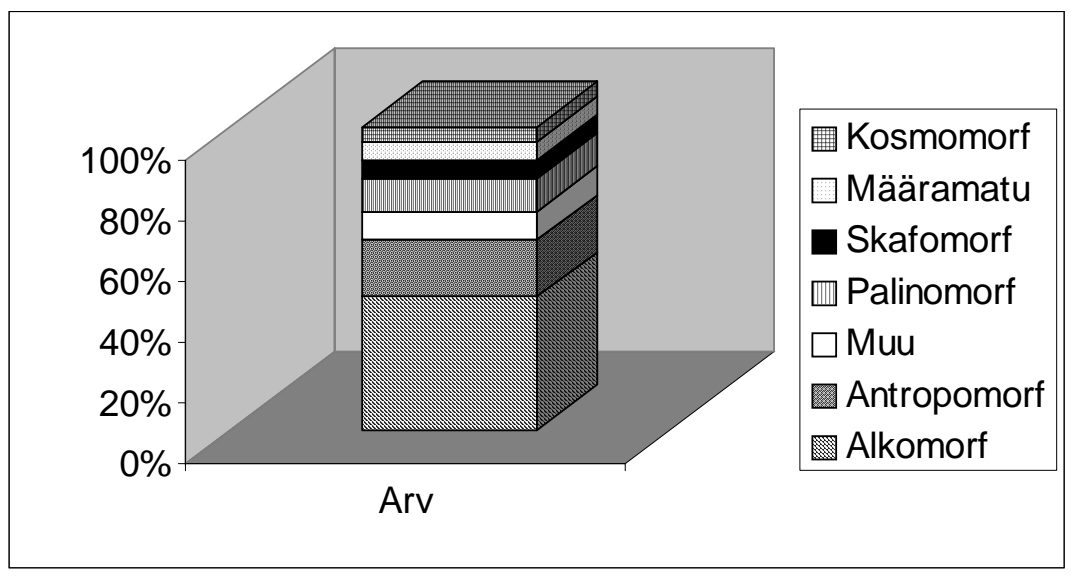

Joonis 12. Tomi petroglüüfid liigiti. 
nud graveeringud kujutavad haruldasi objekte (arvult 1-6). Määramatuks osutus 30 petroglüüfi $(5,8 \%)$.

Äänisjärve leiualal moodustavad hirvlaste kujutised ehk elafomorfid $8 \%$ (üle 5 korra Tomi alkomorfidest harvem), antropomorfid 7\% (2,7 korda) ja skafomorfid 5\% (Poikalainen 1999: 63 jj). Viimaste sagedus sarnaneb Tomi omaga. Teatavasti moodustavad Äänisjärve petroglüüfidest suurema osa linnulaadsed kujutised $(42 \%$, kuid Tomil alla 2\%) ja kosmomorfid (vastavalt 13 ja 5\%).

Seega erineb Tomi kaljutaie peamiste kujutiste esinemissageduse poolest Äänisjärve omast. Kuigivõrra ühtib vaid paadikujutiste ja mõnede väikese esinemissagedusega petroglüüfide (maoja karukujutised; Äänisjärvel kumbagi 0,8\%) osa. Kui Äänisjärve loojate kultusobjektiks oli peamiselt veelind, siis Lääne-Siberis ilmneb dominantne põdrakultus.

\section{Kirjandus}

Barinova, E. 1994. Les gravures rupestres de Novoromanovskaya Pisanitsa de la rivière Tom en Sibérie = Novoromanovskaya Pisanitsa petroglyphs on the river Tom in Siberia. International Newsletter on Rock Art 8, lk 15-18.

Barinova, E. \& Rusakova, I. 1995. Nouveaux sites d'art rupestre pres de la rivière Tom (Sibérie Occidentale) $=$ New Rock Art Sites by the Tom River (West Siberia). International Newsletter on Rock Art 10, lk 8-19.

Kovtun, I. 1993. Petroglifõ Visjaštšego kamnja i hronologija Tomskihh pissanits. Kemerovo.

Martõnov, A. \& Lomteva, A. 1994. Les gravures rupestres de Novoromanovskaya Pisanitsa de la rivière Tom en Sibérie = Novoromanovskaya Pisanitsa petroglyphs on the river Tom in Siberia. International Newsletter on Rock Art 8, lk 18-20.

Okladnikov, A. \& Martõnov, A. 1972. Sokrovištša tomskihh pissanits: Naskalnõje rissunki epohhi neolita i bronzõ. Moskva.

Poikalainen, V. 1999. Some Statistics about Rock-carvings of Lake Onega. Folklore 11, lk 60-69.

Poikalainen, V. \& Ernits, E. 1998. Rock Carvings of Lake Onega: The Vodla Region. Tartu. 